\title{
BENIGN ROLANDIC EPILEPSY
}

\section{CLINICAL AND ELECTROENCEPHALOGRAPHIC CORRELATES}

\author{
RUDIMAR DOS SANTOS RIESGO*, PRASANNA JAYAKAR**, NEWRA TELLECHEA ROTTA***
}

\begin{abstract}
Benign rolandic epilepsy (BRE) is known for its dissociation from structural alterations. Nevertheless, the number of cases with reported organic lesions has been increasing. This led to the creation of two subgroups, "benign" and "non benign" BRE, and resulted in the need for additional parameters to define electrographic benignity. We assessed the possible associations between interictal electroencephalographic findings and clinical behavior in $60 \mathrm{BRE}$ cases, testing four parameters of electrographic benignity (paroxysm morphology, horizontal dipole, base rhythms, laterality of rolandic spikes). We also assessed the relationship between neuroimaging findings and electrographic and clinical classifications, and found a statistically significant association (sensitivity $=73.5 \%$; specificity $=81.8 \%$; positive predictive value $=94.8 \%$; negative predictive value $=40.9 \%$ ). Three of the electrographic parameters proposed were associated with clinical classification: paroxysm morphology, horizontal dipole, and base rhythms. Cases electrographically classified as benign have 21 times more chances to be equally classified as clinically benign according with the tested criteria.
\end{abstract}

KEY WORDS: benign rolandic epilepsy, EEG (electroencephalogram), childhood epilepsy.

\section{Epilepsia rolândica benigna: correlações clínicas e eletrencefalográficas}

RESUMO - A epilepsia rolândica benigna da infância (ERBI) é conhecida por não estar associada a alterações estruturais. Contudo, tem aumentado o número de casos com lesões orgânicas. Tal fato levou à criação de dois subgrupos, "benigno" e "não benigno", e criou a necessidade de definir parâmetros adicionais de benignidade eletrográfica. Nós avaliamos as possíveis associações entre achados do EEG interictal e comportamento clínico em 60 casos de ERBI, testando quatro parâmetros de benignidade eletrográfica (morfologia do paroxismo, dipolo horizontal, ritmos de base e lateralidade das pontas rolândicas). Também foi avaliada a associação entre os achados de neuroimagem e as classificações eletrográfica e clínica; encontrou-se uma associação estatisticamente significativa (sensibilidade $=73,5 \%$; especificidade $=81,8 \%$; valor preditivo positivo $=94,8 \%$; valor preditivo negativo=40,9\%). Três dos parâmetros eletrográficos estiveram associados à classificação clínica: morfologia dos paroxismos, dipolo horizontal e ritmos de base. Casos classificados eletrograficamente como benignos têm chance 21 vezes maiores de serem igualmente classificados como clinicamente benignos, de acordo com os critérios testados.

PALAVRAS-CHAVE: epilepsia rolândica benigna, EEG (eletrencefalograma), epilepsia da infância.

The spikes captured in the rolandic region (centrotemporal) in electroencephalograms (EEG) of children with or without seizures have been described and discussed in detail since the 1950s. The first description of rolandic spikes in children is attributed to Gastaut. ${ }^{1}$ Nayrac \& Beaussart ${ }^{2}$ and Bancaud et $\mathrm{al}^{3}{ }^{3}$ were the first to report an electroclinical syndrome, consisting of reasonably stereotyped seizures and rolandic spikes, today known as benign rolandic epilepsy (BRE) of childhood.

Study developed at the Division of Child Neurology, Hospital de Clínicas de Porto Alegre, Universidade Federal do Rio Grande do Sul (UFRGS), Porto Alegre, Brazil. *M.D., Child Neurologist, Master in Pediatrics, Fellow at the Miami Children's Hospital (Child EEG); **M.D., PhD., Child Neurologist, Director of the Neuroscience Center, Miami Children's Hospital, U.S.A.; ***M.D., PhD., Child Neurologist, Associate Professor of Neurology at UFRGS. Aceite: 6-junho-2000.

Dr. Rudimar dos Santos Riesgo - Rua São Vicente, 513/704 - 90630-180 Porto Alegre RS - Brasil. 
In most cases, epilepsy begins during childhood or adolescence. Informing the parents that a child is affected by this disease demands a full understanding of childhood epilepsy. Lapses in the explanation and diagnostic errors may have a negative influence on the psychosocial adjustment and behavior of the child and of his/her relatives ${ }^{4}$.

BRE is the most common and the best known benign childhood partial epilepsy. It has an auto-limited and age-dependent course. Seizures occur mostly between the ages of three and thirteen; they are unilateral, with maintenance of consciousness, and involve the face, the tongue, and sometimes the arms and legs. EEGs show high voltage, centrotemporal, unilateral or bilateral spike peaks, usually followed by a slow wave, very much activated by sleep, with normal background activity $^{5}$. Although there is a general consensus that BRE is not related to structural alterations, there are reports of BRE with structural lesions ${ }^{6-8}$.

By definition, BRE is a benign condition, presenting neither alterations in the central nervous system (CNS) nor cognitive deficits. However, as a result of descriptions of cases relating BRE to organic lesions, two subgroups emerged: a "functional" or "benign" subgroup, and an "organic" or "non benign" subgroup. Therefore, it became useful to define parameters for electrographic benignity that could be used for prognostic assessment of benign and non benign cases ${ }^{9}$.

Despite the fact that children with rolandic spikes may have or not seizures and structural lesions in the CNS, there are few publications suggesting criteria for electrographic benignity in BRE cases. Therefore, the objective of the present cross-sectional study was to verify the possible association between interictal EEG findings and clinical behavior in $60 \mathrm{BRE}$ cases. In order to accomplish this objective, we tested four criteria for electrographic benignity: rolandic spike morphology, presence (or absence) of horizontal dipoles, aspect of the background activity and laterality of rolandic spikes. We also assessed the possible association between neuroimaging results and clinical and electrographic classifications, as well as the possibility of finding relevant data in the comparison between groups with matching electrographic and clinical classifications and groups without matching classifications.

\section{METHOD}

We carried out a cross-sectional study in which the study factor was the interictal EEG and the outcome was the clinical behavior of BRE cases. The studied population consisted of 60 consecutive BRE cases, plus 31 children with rolandic spikes who did not present seizures, seen at the Neuroscience Center at the Miami Children's Hospital between January 1994 and December 1996.

The first interictal EEG, obtained around the time of the seizures, was taken into consideration. The subsequent EEGs of a same patient were disregarded. Patients who did not complete treatment in the hospital were excluded from the study. Data were collected in standardized files to be entered into a database.

The electrographic variables analyzed were: EEG type, rolandic spike morphology, horizontal dipole, background activity, lateralization of rolandic spikes, and electrographic classification. The clinical variables observed were: sex, presence (or not) of seizures, neurological examination, use of anticonvulsants, results of neuroimaging exams, and clinical classification of BRE.

All exams were performed with a 24-channel Nicolet Voyageur digital electroencephalograph, with time constant adjusted at 0.3 , lead velocity at $30 \mathrm{~mm} / \mathrm{s}$, high frequency filter at $70 \mathrm{HZ}$, and sensibility between 7 $10 \mathrm{uV} / \mathrm{m}$. Electrodes were placed according to the International System $10-20^{10}$. Patients who needed to be sedated received $35-50 \mathrm{mg} / \mathrm{kg}$ of a $20 \%$ solution of chloral hydrate. All patients were examined following the standardized routine of the Neuroscience Center, Miami Children's Hospital.

All EEGs showing rolandic spikes were selected. Paroxysms located at the midtemporal (T3, T4), central $(\mathrm{C} 3, \mathrm{C} 4)$, or (concomitant) centrotemporal ${ }^{11}$ regions were considered as rolandic.

First, a review of the tracing was performed and the exams were classified as "benign" or "non benign." Subsequently, we carried out a review of the clinical data, classifying cases as "benign" or "non benign." During the process of revising the EEGs, the examiner was blinded to the clinical status, and vice-versa.

Electrographically, leads presenting at least three out of the four criteria tested for electrographic benignity (stereotyped paroxysms, presence of horizontal dipole, normal background activity, and bilateral paroxysms) were considered benign. In order to evaluate the morphology of paroxysms and the presence of horizontal dipole, the first ten paroxysms were visually analyzed in the average montage. We considered as stereotyped those 
paroxysms that did not alter either position or morphology. The maximum range admitted between paroxysms was $30 \%$ in duration and $50 \%$ in amplitude. We considered as horizontal dipole the simultaneous visualization of negativity in the centrotemporal region (posterior) and positivity in the frontal region (anterior), as proposed by Jayakar et al. ${ }^{12}$ These two criteria were considered positive when found in at least six out of the 10 (or in $60 \%$ ) available paroxysms. Cerebral base rhythms, analyzed in routine bipolar montages and also in average montages, were considered normal when adequate for the patient's age and when focal slowness did not occur. Lateralization of the first ten paroxysms was investigated in routine montages as well as in average montages; lateralization was considered bilateral when at least one unequivocal paroxysm was identified in each side of the tracing.

Three parameters were established for clinical benignity. We considered as clinically benign those cases without delay in neuropsychomotor development, without alteration in the neurological examination, and without detectable lesions upon neuroimaging exams, when available. The age at the beginning of seizures was not considered for the clinical classification.

Results were analyzed using the SPSS software, version 6, under the supervision of the Postgraduate Studies Research Group, Hospital de Clínicas de Porto Alegre. In order to examine the agreement between the electrographic and clinical behaviors, the Kappa coefficient was used. Sensitivity and specificity analyses were performed, and the positive and negative predictive values were calculated. A bivariate analysis (chi-square test and Fisher's exact test) was carried out with each of the studied factors, in order to verify their association with clinical behavior. Statistically significant and clinically relevant factors were assessed and submitted to a logistic regression model. We adopted a $5 \%$ level of statistical significance.

\section{RESULTS}

From January 1994 to December 1996, 5,524 EEGs were performed at the Miami Children's Hospital, out of which 116 presented rolandic spikes in the patient's first monitoring. Twenty-five exams from patients who did not complete treatment in the hospital were excluded, so that 91 EEGs with rolandic spikes remained. Out of these, 60 were from children with rolandic spikes and seizures, fulfilling the criteria for BRE. From the 60 EEGs, 31 (51.6\%) were carried out during sleep and awake state, $19(31.7 \%)$ during awake state, and 10 (16.7\%) were carried out during sleep.

From the 60 children with BRE included in this study, 32 (53.3\%) were male. The age at the first seizure varied from 1 to 14 years $($ mean $=6.04$ years; standard deviation $=2.82$; median $=5.5$ years; and $=7$ years).

Regarding other concomitant clinical findings, 33 patients had associated diseases; in some patients, more than one associated disease was present. We observed attention-deficit hyperactive disorder (ADHD) in eight cases; behavioral problems and mental retardation in five cases; headaches in four cases; perinatal asphyxia, febrile convulsions, migraine, cerebral palsy and subarachnoid hemorrhage in two cases; speech disorders, breathlessness crises, hydrocephalus, tuberous scleroses, neonatal acute bacterial meningitis, and hypoacusia in each one.

Fifty-five patients were submitted to neuroradiologic evaluation, out of which 45 (81.8\%) were normal. Regarding the 10 altered exams, six showed variable degrees of cortical atrophy, two showed subarachnoid hemorrhage, one tuberous scleroses, and one hydrocephalus.

Out of the 60 BRE cases, $38(63.3 \%)$ received the electrographical classification "benign," and $49(81.7 \%)$ received the clinical classification "benign." There was agreement between the two classifications in $45(75 \%)$ and disagreement in $15(25 \%)$ cases (Figure 1). The parameters for electrographic benignity observed were stereotyped rolandic spikes in $60 \%$ of the leads; horizontal dipole in $75 \%$; normal background activity in 70\%; and bilateral paroxysms in $41.7 \%$ of the EEGs. The concordant and the discordant subgroups were compared regarding sex, age of the first seizure, neurological examination, parameters for electrographic benignity, use of anticonvulsant and neuroimaging findings (Table 1).

Among the 11 cases clinically classified as "non benign," some presented more than one of the parameters taken into consideration. Eight cases presented delayed neuropsychomotor development, five presented alterations in the neurological exam and nine cases presented alterations in the neuroimaging exams. 


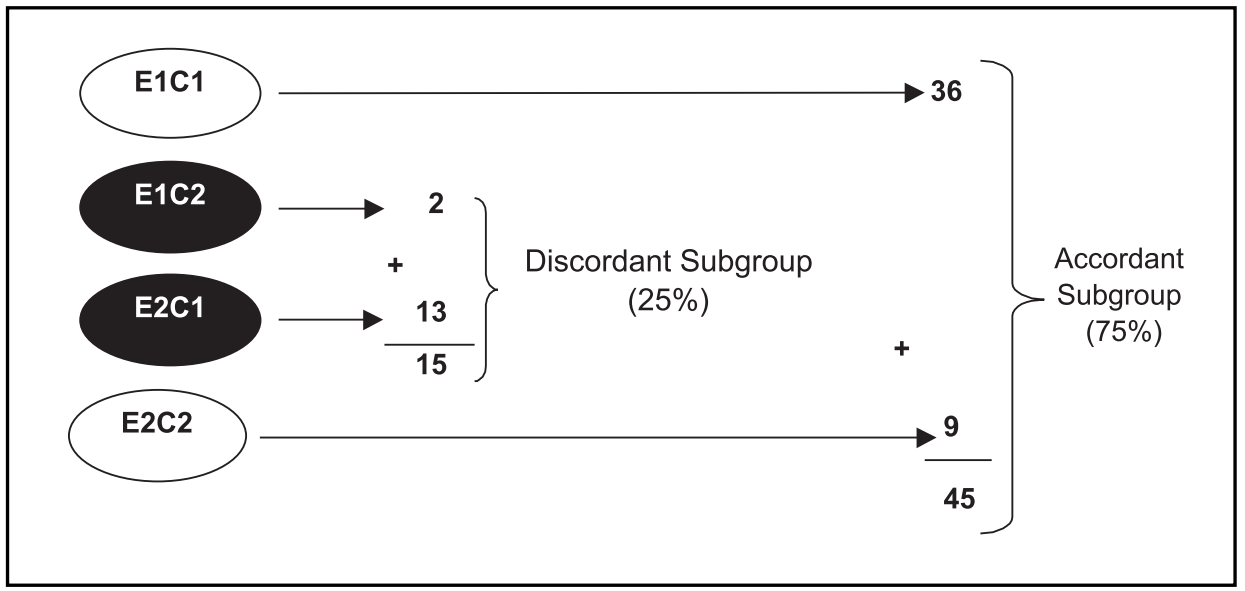

Fig 1. Electrographic and clinical behavior in BRE subgroups.

E, electrographic; $C$, clinical; 1, benign; and 2, non benign.

Table 1. Comparison between the concordant and discordant subgroups in benign rolandic epilepsy cases $(n=60)$.

\begin{tabular}{|c|c|c|c|c|c|}
\hline \multirow[t]{2}{*}{ Parameter } & \multicolumn{2}{|c|}{ Concordant subgroup } & \multicolumn{2}{|c|}{ Discordant subgroup } & \multirow[t]{2}{*}{$\mathrm{p}$ value } \\
\hline & $\mathrm{n}=45$ & $100 \%$ & $\mathrm{n}=15$ & $100 \%$ & \\
\hline Male & 23 & (71.9) & 9 & $(28.1)$ & Not significant \\
\hline Female & 22 & $(78.6)$ & 6 & $(21.4)$ & \\
\hline Seizures at 3 or - years & 6 & $(66.7)$ & 3 & $(33.3)$ & Not significant \\
\hline Seizures at +3 years & 39 & $(76.5)$ & 12 & $(23.5)$ & \\
\hline Stereotyped spikes & 34 & $(94.4)$ & 2 & $(5.6)$ & Significant $p=0.00008$ \\
\hline Non-stereotyped spikes & 11 & $(45.8)$ & 13 & $(54.2)$ & \\
\hline Presence of dipole & 38 & $(82.6)$ & 8 & $(17.4)$ & Significant $\mathrm{p}=0.03$ \\
\hline Absence of dipole & 7 & $(50.0)$ & 7 & $(50.0)$ & \\
\hline Normal base rhythms & 38 & $(90.5)$ & 4 & $(9.5)$ & Significant $p=0.00007$ \\
\hline Abnormal base rhythms & 7 & $(38.9)$ & 11 & $(61.1)$ & \\
\hline Unilateral spikes & 27 & $(77.1)$ & 8 & $(22.9)$ & Not significant \\
\hline Bilateral spikes & 18 & $(72.0)$ & 7 & $(28.0)$ & \\
\hline With anticonvulsant & 24 & $(72.7)$ & 9 & $(27.3)$ & Not significant \\
\hline Without anticonvulsant & 21 & $(77.8)$ & 6 & $(22.2)$ & \\
\hline Normal neuroimaging & 34 & $(75.6)$ & 11 & $(24.4)$ & Not significant \\
\hline Abnormal neuroimaging & 8 & $(80.0)$ & 2 & $(20.0)$ & \\
\hline
\end{tabular}


Table 2. Electroclinic association in benign rolandic epilepsy cases*.

\begin{tabular}{lcccccc}
\hline Classification & \multicolumn{2}{c}{$\begin{array}{c}\text { Clinically } \\
\text { benign }\end{array}$} & \multicolumn{2}{c}{$\begin{array}{c}\text { Clinically } \\
\text { non-benign }\end{array}$} & \multicolumn{2}{c}{ Total } \\
\cline { 2 - 7 } & $\mathrm{n}$ & $(\%)$ & $\mathrm{n}$ & $(\%)$ & $\mathrm{n}$ & $(\%)$ \\
\hline Benign EEG & 36 & $(94.7)$ & 2 & $(5.3)$ & 38 & $(100)$ \\
Non benign EEG & 13 & $(59.1)$ & 9 & $(40.9)$ & 22 & $(100)$ \\
Total & 49 & $(81.7)$ & 11 & $(18.3)$ & 60 & $(100)$ \\
\hline
\end{tabular}

$* n=60 ; P=0.00109$.

Table 3. Parameters for electrographic benignity and clinical classification in benign rolandic epilepsy.

\begin{tabular}{lccccc}
\hline Parameter & \multicolumn{2}{c}{$\begin{array}{c}\text { Clinically } \\
\text { benign }\end{array}$} & \multicolumn{2}{c}{$\begin{array}{c}\text { Clinically } \\
\text { non-benign }\end{array}$} & p value \\
\cline { 2 - 6 } & $\mathrm{n}$ & $(\%)$ & $\mathrm{n}$ & $(\%)$ & \\
\hline Stereotyped paroxysms & 34 & $(94.4)$ & 2 & $(5.6)$ & $\mathbf{0 . 0 0 4}$ \\
Non-stereotyped paroxysms & 15 & $(62.5)$ & 9 & $(37.5)$ & \\
Presence of horizontal dipole & 41 & $(91.1)$ & 4 & $(8.9)$ & $\mathbf{0 . 0 1}$ \\
Absence of horizontal dipole & 8 & $(53.3)$ & 7 & $(46,7)$ & \\
Normal cerebral rhythms & 39 & $(92.9)$ & 3 & $(7.1)$ & $\mathbf{0 . 0 0 2}$ \\
Abnormal cerebral rhythms & 10 & $(55.6)$ & 8 & $(44.4)$ & \\
Unilateral paroxysms & 28 & $(80.0)$ & 7 & $(20.0)$ & 0.74 \\
Bilateral paroxysms & 21 & $(84.7)$ & 4 & $(16.0)$ & \\
\hline
\end{tabular}

A statistically significant association was observed between the proposed clinical and electrographic classifications (Table 2$)$. This association showed a statistically $(\mathrm{p}=0.0003)$ significant Kappa coefficient of 0.39 . The sensitivity of this association was $73.5 \%$, the specificity was $81.8 \%$, the positive predictive value was $94.7 \%$ and the negative predictive value was $40.9 \%$.

In terms of parameters for electrographic benignity and clinical classification in BRE patients, among the four criteria for electrographic benignity, rolandic spikes morphology, presence of horizontal dipole and aspect of cerebral background activity were associated with the clinical classification in a statistically significant manner. The unilateral or bilateral characteristic of rolandic spikes was not a determining factor in the association between the electrographic and clinical classification in our group (Table 3 ).

Concerning to clinical classification and demographic data, there was no statistically significant association between the age at first seizure (with the sample stratified in two age groups, $\leq 3$ years or $>3$ years) and clinical classification. There was no significant association between sex and clinical 
Table 4. Neuroradiologic evaluation, clinical and electrographic classification in benign rolandic epilepsy cases*.

\begin{tabular}{lcccccc}
\hline Imaging exam & \multicolumn{3}{c}{ Clinically* } & \multicolumn{3}{c}{ Electrographically** } \\
\hline & $\begin{array}{c}\text { Benign } \\
\mathrm{n}(\%)\end{array}$ & $\begin{array}{c}\text { Non benign } \\
\mathrm{n}(\%)\end{array}$ & $\begin{array}{c}\text { Total } \\
\mathrm{n}(\%)\end{array}$ & $\begin{array}{c}\text { Benign } \\
\mathrm{n}(\%)\end{array}$ & $\begin{array}{c}\text { Non benign } \\
\mathrm{n}(\%)\end{array}$ & $\begin{array}{c}\text { Total } \\
\mathrm{n}(\%)\end{array}$ \\
\hline Normal & $43(95.6)$ & $2(4.4)$ & $45(100)$ & $32(71.1)$ & $13(28.9)$ & $45(100)$ \\
Abnormal & $1(10.0)$ & $09(90.0)$ & $10(100)$ & $2(20.0)$ & $8(80.0)$ & $10(100)$ \\
Total & $44(80.0)$ & $11(20.0)$ & $55(100)$ & $34(61.8)$ & $21(38.2)$ & $55(100)$ \\
\hline
\end{tabular}

$*_{\mathrm{n}}=55 ; \mathrm{p}<0.0001 . * *_{\mathrm{n}}=55 ; \mathrm{p}=0.00426$.

Table 5. Multivariate analysis of benignity criteria in benign rolandic epilepsy cases.

\begin{tabular}{|c|c|c|c|c|}
\hline & \multicolumn{2}{|c|}{ Crude analysis } & \multicolumn{2}{|c|}{ Multivariate analysis } \\
\hline & Odds ratio & (CI 95\%) & Odds ratio & (CI 95\%) \\
\hline \multicolumn{5}{|c|}{ Electrographic classification } \\
\hline Benign & 25.0 & $(2.92-214.1)$ & 21.0 & $(2.18-203.1)$ \\
\hline Non benign & 1.0 & & & \\
\hline \multicolumn{5}{|l|}{ Age group } \\
\hline$\leq 3$ years & 0.28 & $(0.06-1.5)$ & 0.22 & $(0.03-1.7)$ \\
\hline$>3$ years & 1.0 & & & \\
\hline
\end{tabular}

classification, although there was a greater number of boys who were clinically diagnosed as "non benign."

The results of the neuroradiologic evaluation and the clinical classification showed a strong association, with a predominance of normal results among the "benign" cases (Table 4). There was also a statistically significant association between the neuroimaging evaluation and the electrographic classification. Among the abnormal radiological exams, $80 \%$ had been previously classified as "non benign" (Table 4).

Multivariate analysis of the benignity criteria for BRE: the three statistically significant criteria for electrographic benignity were included along with the clinical relevant criterion, which was age at first seizure, with the cutoff point at the age of three (Table 5).

\section{DISCUSSION}

In the 90s, the association between childhood BRE and other clinical entities was established, sometimes by chance ${ }^{13}$. In fact, since the 70 s, several reports have been published describing the association of BRE and other diseases, for example, between BRE and cerebral palsy ${ }^{13,14}$, primary generalized epilepsy ${ }^{15}$, benign epilepsy with occipital paroxysms ${ }^{16}$; neuronal migration disorders ${ }^{8}$; febrile convulsions ${ }^{17}$; cerebral tumors $^{9}$; arachnoid cysts $^{18}$; agenesis of corpus callosum ${ }^{7}$; fragile $\mathrm{X}$ syndrome $^{19}$; Foix-Chavany-Marie syndrome ${ }^{20}$; Landau-Kleffner syndrome ${ }^{21}$; Rett syndrome ${ }^{22,23}$ and continuous spike-wave during slow-wave sleep ${ }^{24}$, among others.

Most publications regarding childhood epilepsy report a clear predominance of cases affecting males $^{25}$, especially between the ages of 5 and 10 . This is also valid for BRE cases, which affects boys and girls ${ }^{5}$ in a proportion of $6: 4^{5}$. In the present study, $53.3 \%$ of the cases were boys. We noticed a greater coincidence between the electrographic and clinical classification of girls, and a 
higher percentage of discordant cases among boys, although values were not statistically significant. We also observed a higher percentage of "non benign" cases among boys, both clinically and electrographically. This predominance of the male sex is probably a consequence of the BRE prevalence on boys, as described by Holmes ${ }^{13}$.

There is consensus regarding the notion that BRE is an age-dependent and auto-limited illness, which usually begins at the age of three and spontaneously disappears around the age of thirteen, with a peak at the age of seven ${ }^{5}$. This age dependence is also true for the development of rolandic spikes, and they are related to functional maturation rather than to the presence lesions, since they occur simultaneously with certain phases of the CNS maturation and are probably related (especially the inferior portion of the rolandic fissure) to the myelinization of the surroundings of the cerebral motor area ${ }^{26}$. The average age at the beginning of seizures, in our group, was 6.04 years, ranging from one to 14 years, which is in agreement with the findings of Legarda et al. ${ }^{27}$ The early start of seizures is associated to febrile convulsions, and not to the typical rolandic crisis. The age at the first seizure in our sample was not associated with the clinical behavior of BRE, which is in agreement with Ambrosetto ${ }^{8}$ and in disagreement with the findings of Dravet ${ }^{5}$.

In our study, the percentage of EEGs showing rolandic spikes without seizures was of $31.4 \%$. This finding does not differ from previously described values, that range from $17 \%$ up to almost $50 \%$. In our sample, sleep and awake EEGs were performed in 51.6\% the cases; awake EEGs in $31.7 \%$; and sleep EEGs in $16.7 \%$; these results are similar to those obtained by Shinnar et al. ${ }^{28}$. Amongst us, Borges et al. ${ }^{29}$ carried out a nine-year prospective study of 412 EEGs with rolandic spikes from 160 children with or without epilepsy. Surprisingly, $84.4 \%$ of the recordings in that prospective study were carried out in the awake state, despite the fact that the study's objective was to evaluate the natural history of rolandic spikes.

Among the 31 cases of EEGs showing rolandic spikes without concomitant seizures in our sample, there was a predominance of behavioral problems, most frequently ADHD, followed by headaches, which is in agreement with previous findings ${ }^{29}$. The presence of one child with Rett syndrome, and of another child with autism in our sample, both with concomitant rolandic spikes, is not surprising. The association of rolandic spikes and certain stages of Rett syndrome has been previously described ${ }^{22}$, and was recently confirmed ${ }^{23}$. We observed three cases with speech disorders, two in the group without convulsions and one in the group with BRE; it is possible that these cases present similarities with those described by Roulet et al. ${ }^{30}$, and also by Deonna et al. ${ }^{31}$.

There is a consensual notion that in benign childhood partial epilepsies, among which BRE is included, the child develops without any physical, intellectual, or neurological deficit ${ }^{5}$. However, rolandic spikes, with or without seizures, can be found in children with or without organic lesions $\mathrm{s}^{5,6}$. Therefore, in addition to defining electrographic benignity criteria that will allow an adequate electrographic classification, the neuroradiologic evaluation has become an important auxiliary tool for the classification of BRE cases. Nevertheless, there are few studies of BRE with simultaneous neuroradiologic evaluation ${ }^{32}$.

In the present study, the neuroradiologic evaluation was used whenever available to classify BRE cases in the clinical point of view, together with the evaluation of neuropsychomotor development and with the neurological examination. We performed a neuroradiologic evaluation in $91.7 \%$ of BRE cases, a much higher percentage than that reported by previous studies ${ }^{32}$. Neuroradiologic data are extremely useful in studies testing the association between clinical and electrographic behaviors, such as the present study. Our most relevant finding was the statistically significant association between the neuroradiologic evaluation and the electrographic classification. Among the cases with an abnormal evaluation, $80 \%$ had already been electrographically classified as "non benign". The literature reviewed did not reveal any data that could be compared to ours.

Despite the paucity of publications specifically proposing parameters of electrographic benignity for BRE cases, same parameters, such as morphology of rolandic spikes, exact location of 
paroxysms, prognostic value of generalized paroxysms, relation between the intensity of rolandic spikes and level of consciousness, polysomnographic evaluations, "double spike phenomenon," and studies with brain mapping, were already tested in an attempt to predict the clinical evolution of specific cases $^{33-36}$.

The review of previous reports leads to the impression that stereotyped rolandic spikes, characterized by high amplitude and small duration and intensely activated by sleep, are "benign" 37 . The present results suggest the existence of a statistically significant association between the morphology of rolandic spikes and the clinical classification of BRE. Among the cases that were clinically classified as "benign," there was a predominance of stereotyped rolandic spikes. Similarly, there was a predominance of stereotyped rolandic spikes in the subgroup with agreement between the electrographic and clinical classifications. When the concordant and discordant subgroups were tested for this specific parameter, a statistically significant difference was found, which is in agreement (in spite of the methodological differences) with the results of Van Der Meij et al. ${ }^{37}$.

Since the late 80 s, and during the first half of the 90 s, some works evaluating the possible relation between horizontal dipoles and clinical behavior in BRE were developed simultaneously with the first experiences with digital EEG and brain mapping ${ }^{11,12,34,36}$. Initial reports tended to give greater prognostic importance to horizontal dipoles ${ }^{11}$; more recent reports, however, have failed to demonstrate the prognostic value of horizontal dipoles in $\mathrm{BRE}^{36}$. In our $60 \mathrm{BRE}$ cases, we observed a statistically significant association between the presence of horizontal dipoles in the EEG and the finding of coincidence or discordance between the clinical and electrographic classifications, as well as between the presence of dipoles and the subsequent clinical classification of each case. Among the cases that were clinically classified as "benign," the horizontal dipole was the most common finding. Our results (in spite of the methodological differences) agree more with the results obtained by Gregory \& Wong ${ }^{11}$, and disagree with the findings of Braga ${ }^{36}$.

The cerebral base rhythms observed in routine EEGs depend upon several variables, such as the child's level of consciousness; the possible impact of the sedation used to obtain sleep; the child's age; the possible structural lesions in the CNS; and the interictal paroxystic activity, which, when intense, can affect base rhythms $s^{6,9,13,32,36,38,39}$. In benign cases, the cerebral base rhythms could be expected to be normal. Our sample shows that the relation between cerebral base rhythms and clinical classification was significant. Among cases posteriorly classified as clinically benign there was predominance of normal EEG background. That did not happened in the clinically non benign cases. It is difficult to compare our findings with those of other published studies, since few studies have taken this specific parameter into consideration, and used other methodological approaches ${ }^{36}$.

It would be reasonable to imagine that unilateral rolandic spikes are more prone to be associated with CNS pathologies, whereas bilateral or unilateral spikes that do not remain fixed in one specific side would have a more dysfunctional character. In terms of intensity and amplitude of the rolandic spike, in addition to a time-dependent evolution, it is known that the passing of time may also determine a migration of paroxysms from one side of the brain to the other in the case of unilateral spikes, or even a temporary disappearance with posterior reappearance ${ }^{11,26,29}$. In our study, we proposed that bilateral rolandic spikes would be one of the criteria for electrographic benignity for BRE. There are very few works relating the lateralization of rolandic spikes to clinical behavior in BRE cases. According to Gregory \& Wong ${ }^{11}$, the unilaterality or bilaterality of the spikes is not important for prognostic purposes. In our sample, we observed a predominance of unilateral spikes in cases that received a "non benign" classification, but statistically significant levels were not attained. When the concordant and discordant subgroups were compared in terms of the electrographic parameter, the association was not significant either.

We concluded that there is a statistically significant association between interictal EEG findings and clinical behavior in BRE cases. This association has a sensitivity of $73.5 \%$; a specificity of $81.8 \%$; a positive predictive value of $94.8 \%$ and a negative predictive value of $40.9 \%$. Among the four electrographic criteria evaluated for BRE, three were significantly associated with clinical 
classification: rolandic spike morphology, presence of horizontal dipole and aspect of background activity. The unilaterality or bilaterality of the rolandic spikes was not associated with clinical behavior. Neither the age at the first seizures nor sex were associated with the clinical classification of BRE. There was a statistically significant association between neuroimaging findings and the electrographic and clinical classifications. Through multivariate analysis, we observed that a case that had received electrographic classification of benignity had 21 times more chance of also receiving a clinical classification of benignity, according to the criteria proposed in this study.

Acknowledgements - The authors thank the staff at the Miami Children's Hospital for welcoming Dr. Rudimar dos Santos Riesgo and providing optimal opportunities during his training, including access to the data that made this work possible. The authors also thank Professor Frederico D. Kliemann for his support.

\section{REFERENCES}

1. Gastaut Y. Un élément déroutant de la séméiologie électroencéphalographique: les pointes prérolandiques sans signification focale. Rev Neurol 1952;87:488-490.

2. Nayrac $P$, Beaussart M. Les pointes prérolandiques: expression électroencéphalographique très particulière. Étude électroclinique de 21 cas. Rev Neurol 1958;99:201-206.

3. Bancaud J, Colomb D, Dell MB. Les pointes rolandiques: un symptôme EEG popre à l'enfant. Rev Neurol 1958;99:206-209.

4. Panayiotopoulos CP. Benign childhood partial epilepsies: benign childhood seizure susceptibility syndromes. J Neurol Neurosurg Psychiatry 1993;56:02-05.

5. Dravet C. Benign epilepsy with centrotemporal spikes: do we know all about it? In Wolf P. editor. Epileptic seizures and syndromes. London: John Libbey, 1994. p.231-240.

6. Morikawa T, Tenaguchi N, Shigematsu H et al. Functional partial epilepsies in childhood. Jpn J Psychiatry Neurol 1986;40:301-306.

7. Santanelli P, Bureau M, Magaudda A, Gobbi G, Roger J. Benign partial epilepsy with centro-temporal (or rolandic) spikes and brain lesion. Epilepsia 1989;30:182-188.

8. Ambrosetto G. Treatable partial epilepsy and unilateral opercular neuronal migration disorder. Epilepsia 1993;34:604-608.

9. Shevell MI, Rosenblatt B, Watters GV, O'Gorman AM, Montes JL. "Pseudo-BECRS": intracranial focal lesions suggestive of a primary partial epilepsy syndrome. Pediatric Neurol 1996;14:31-35.

10. Jasper HH. Report of the Committee on Methods of Clinical Examination in Electroencephalography. Electroencephalogr Clin Neurophysiol 1958;10:370-375.

11. Gregory DL, Wong PKH. Clinical relevance of a dipole field in rolandic spikes. Epilepsia 1992;33:36-44.

12. Jayakar P, Duchowny M, Resnik T, Alvarez LA. Localization of seizure foci: pitfalls and caveats. J Clin Neurophysiol 1991;8:414-431.

13. Holmes GL. Rolandic epilepsy: clinical and electroencephalographic features. In Degen R, Dreifuss FE. editors. Benign localized and generalized epilepsies of early childhood. Amsterdam: Elsevier 1992:29-43.

14. Lerman P, Kivity S. Benign focal epilepsy of childhood: a follow-up study of 100 recovered patients. Arch Neurol 1975;32:261-266.

15. Niedermeyer E. Complexities of primary generalized epilepsy. Clin Electroencephalogr 1981;12:177-191.

16. Fonseca LC, Tedrus GM. Paroxismos occipitais após o fechamento dos olhos: correlações clínico-eletrencefalográficas em 24 casos. Arq Neuropsiquiatr 1994;52:510-514.

17. Kajitani T, Ueoka K, Nakamura M, Kumanomidou Y. Febrile convulsions and rolandic discharges. Brain Dev 1981;3:351-359.

18. Tsuji M, Muroi J, Yorifuji T, Shimizu K, Okuno T. A case of benign epilepsy of children with centro-temporal EEG foci with multiple arachnoid cysts. No To Hattatsu 1994;26:418-422.

19. Sanfilippo S, Ragusa RM, Musumeci SA, Neri G. Fragile-X mental retardation: prevalence in a group of institutionalized patients in Italy and a novel EEG pattern. Am J Med Genet 1986;23:589-595.

20. Pratz JM, Garaizar C, Garcia-Nieto ML, Madoz P. El síndrome opercular epiléptico: una forma peculiar de epilepsia parcial benigna de la infancia com paroxismos rolándicos. Rev Neurol (Barc) 1999;29:375-380.

21. Aicardi J. El síndrome de Landau-Kleffner. Rev Neurol (Barc) 1999;29:380-385.

22. Niedermeyer E, Naidu S. Further EEG observations in children with Rett syndrome. Brain Dev 1990;12:53-54.

23. Valente KDR, Andrade JQ, Grossmann RM. Síndrome de Rett: relação dos padrões eletrencefalográficos com o estadiamento clínico. Arq Neuropsiquiatr 1999;57(Supl 2):16.

24. Jayakar P, Seshia SS. Electrical status epilepticus during slow-wave sleep: a review. J Clin Neurophysiol 1991;8:299-311.

25. Winckler MIB, Rotta NT. Prognostic factors for recurrence of a first seizure during childhood. Arq Neuropsiquiatr 1997;55:749-756.

26. Nishiura N, Miyazaki T. Clinico-electroecephalographical study of focal epilepsy with special reference to "benign epilepsy of children with centro-temporal EEG foci" and its age dependency. Folia Psychiatr Neurol Jpn 1976;30:253-261.

27. Legarda S, Jayakar P, Duchowny M, Alvarez L, Resnik T. Benign rolandic epilepsy: high central and low central subgroups. Epilepsia 1994;35:1125-1129.

28. Shinnar S, Kang H, Berg AT, Goldensohn ES, Hauser A, Moshé SL. EEG abnormalities in children with a first unprovoked seizure. Epilepsia 1994;35:471-476.

29. Borges MA, Godoy MF, Scarabel M. Idade de aparecimento e desaparecimento das pontas rolândicas em 160 crianças acompanhadas ambulatorialmente: um estudo atuarial. Arq Neuropsiquiatr 1999;57:793-797. 
30. Roulet E, Deonna T, Despland PA. Prolonged intermittent drooling and oromotor dyspraxia in benign childhood epilepsy with centrotemporal spikes. Epilepsia 1989;30:564-568.

31. Deonna T, Roulet E, Fonton D, Marcoz JP. Prolonged speech and oromotor deficits of epileptic origin in benign partial epilepsy with rolandic spikes: relationship to acquired aphasia. Neuropediatrics 1993;24:83-87.

32. Morikawa T, Osawa T, Ishiharo O, Seino M. A reappraisal of "benign epilepsy of children with centro-temporal EEG foci". Brain Dev 1979;1:257-265.

33. Dalla Bernardina B, Beghini G. Rolandic spikes in children with and without epilepsy: 20 subjects polygraphically studied during sleep. Epilepsia 1976;17:161-167.

34. Gregory DL, Wong PK. Topographical analysis of the centrotemporal discharges in benign rolandic epilepsy of childhood. Epilepsia 1984;25:705-711.

35. Beydoun A, Garofalo EA, Drury I. Generalized spike-waves, multiple foci, and clinical course of children with EEG features of benign epilepsy of childhood with centrotemporal spikes. Epilepsia 1992;33:1091-1096.

36. Braga NIO. Análise quantitativa do eletrencefalograma de pacientes com descargas epileptiformes rolândicas. Tese, Universidade Federal de São Paulo. São Paulo, 1998.

37. Van Der Meij W, Van Huffelen AC, Wieneke GH, Willemse J. Sequential EEG mapping may differentiate "epileptic" from "non-epileptic" rolandic spikes. Electroenceph Clin Neurophysiol 1992;82:408-414.

38. Castro CBB, Chisté MA, Vizioli JF, et al. Comparação entre o eletrencefalograma de sono natural e o induzido por hidrato de cloral em relação às alterações paroxísticas e ao ritmo de base. Arq Neuropsiquiatr 1994;52:326-329.

39. Nunes, RG, Biagini JC Jr, Valente KDR, Braga NIO, Grossmann RM. Pseudo-alentecimento focal do EEG na epilepsia benigna da infância com descargas centro-temporais. Arq Neuropsiquiatr 1999;57(Supl 2):19. 